\title{
Trend of home or hospital delivery and child birth among Muslim women of Biratnagar, Nepal
}

\author{
BR Pokhrel ${ }^{1}$, P Sharma $^{2}, \mathrm{~N} \mathrm{Jha}^{3}$ \\ School of Health \& Allied Sciences ${ }^{1}$, Pokhara University, Nepal \\ Center for Population and Development ${ }^{2}$, Purbanchal University, Biratnagar, Nepal \\ Karnali Academy of Health Sciences ${ }^{3}$, Jumla, Nepal.
}

\begin{abstract}
Background: Maternal morbidity and mortality remains one of the biggest public health challenges in Nepal. This paper explores the trend of home or hospital delivery and child birth in certain ethnic group. The illiteracy women's low socio economic status in the society, lack of access and difficult geographical rugged terrain are major reasons for not delivering children in health institutions in Nepal. Objective: To find out the trend of hospital or home delivery among Muslim women of Biratnagar city. Methods: Cross-sectional study was conducted among 200 Muslim women of ward 7 of Biratnagar municipality. They were interviewed to assess their health seeking trend of home or hospital delivery and child birth along with factors associated with the use of health services. Information's on usages of health services, education level, family structure, and occupational status information were also collected using a pre-tested and structured questionnaire. Results: The overall institutional delivery in the study population was $24.5 \%$. Illiteracy, low socio-economic status, and poverty in women are the major challenging features of not delivering babies in health institutions. Conclusion: Only one fourth of the women of the study population had hospital/health institutional delivery. Hospital deliveries were seen among the educated women with many antenatal visits. Therefore female education must be encouraged in this community.
\end{abstract}

Key words: Child birth; home delivery, hospital delivery, Muslim women; Nepal.

\section{Introduction}

Maternal mortality is a major concern of

\footnotetext{
Address for correspondence

Mr. Babu Ram Pokhrel

Lecturer

School of Health \& Allied Sciences

Faculty of Science \& Technology Pokhara University

PO Box: 427, Lekhnata-12 Kaski, Nepal

E-mail: pokhrelssm@yahoo.com
}

maternal health in developing countries. ${ }^{1}$ Access to quality care during pregnancy and especially at delivery seems to be crucial factor in explaining the disparity in maternal mortality and morbidity between the 
developing and the industrialized world. ${ }^{2}$ Key health care interventions can largely prevent women dying from pregnancy related causes. Attendance of antenatal care, delivery in medical setting and having a skilled health worker at delivery improve maternal health. ${ }^{3-5}$ However use of these interventions is limited in developing countries. $^{6}$ Only a small proportion of births of currently adolescence women are delivered at health institutions accounting 3 to $11 \%$ birth in Bangladesh, Nepal and Pakistan. Consistent with this finding it is also observed that over $70 \%$ of birth by women of all age groups still remains unattended by trained health workers in all countries of the regions. The proportion of birth of currently married women attended by health workers in Nepal is $14 \%$. Young women and their children are facing serious health risks from early pregnancy and childbirth. More adolescence girls die from pregnancy related causes then from many other causes. ${ }^{7}$ Maternal mortality is estimated to be 281 per 100,000 live births in Nepal in $2009,{ }^{8}$ and the need for treatment of women with obstetric competition is inadequately meet. ${ }^{9}$ Child birth is a risk-producing event, and timely and adequate medical care for women who experience obstetric complications is an option for mitigation the risk. ${ }^{10}$ There is less report available of such study undertaken about the trend of home or hospital delivery in child birth among Muslim women in Nepal. No data available based on the ethnic groups. So this study had been conducted to find the trend of home or hospital delivery among Muslim women of Biratnagar city in eastern Nepal.

\section{Methods}

This cross-sectional study was undertaken in ward no. 7 of Biratnagar Municipality in Morang district. The study population was married Muslim women in the child bearing age group (15-49 years), residing in the study area, who have at least a live baby about 5 years preceding the survey. Health seeking behavior (delivery hospital or home) during child birth was defined as the women having attended whether government (including subhealth post/ health post, PHCC or hospitals) or private institutions and nursing homes. The study duration was January to June 2009. House-to-house visits in the targeted municipal location to find out the eligible women by the investigator before data collection were made with the cooperation of Female Community Health Volunteers (FCHVs) and community leaders. The purposive sampling method was adopted to identify the eligible mothers who met our required criteria. All the 200 mothers were interviewed by using pretested questionnaire with the help of FCHV and community leaders after taking their consent. 
Data were entered and analyzed using SPSS version 10. Bivariate analysis was done to find the association of socioeconomic, demographic and behavioral characteristics with previously used health seeking behavior in pregnancy and child birth. Analysis was also done to determine any relationship between their self reported education level including their spouses occupation, monthly household income and health seeking behavior among reproductive age group (15-49 yrs) women. $p$ value was set at $5 \%$ level of significance.

\section{Results}

A total of 200 Muslim women between 15 to 49 years age group were interviewed for data collection. Most (64.5\%) women were from nuclear family (Table 1). Family head were mainly their husbands (67.5\%) followed by father in laws $(26 \%)$. Only $2.5 \%$ women were head of family among the study population. They lived mainly in thatched houses (69\%), and didn't have toilet (59\%).Their main source of household energy of cooking fuel was firewood $(80.5 \%)$, followed by cow dung (10.5\%). Only (6.5\%) used both LPG gas and firewood for the same purpose. Most (90\%) of the households used tube wells for drinking water. The most $(60.5 \%)$ of women were married between $18-20$ years of age. Only $7 \%$ of women were married above the age of 20 years.

Table 1: Socio-economic and demographic characteristics of the respondents

\begin{tabular}{|l|l|l|}
\hline \multicolumn{1}{|c|}{ Characteristics } & Frequency $(\mathbf{n = 2 0})$ & \multicolumn{1}{c|}{ Percentage } \\
\hline Family structure & & 64.5 \\
\hline Nuclear & 129 & 35.5 \\
\hline Joint & 71 & \\
\hline Household head & & 26 \\
\hline Father in-law & 52 & 4 \\
\hline Mother in-law & 8 & 67.5 \\
\hline Husband & 135 & 2.5 \\
\hline Herself & 5 & \\
\hline Type of house & & 10 \\
\hline Concrete & 20 & 21 \\
\hline Tiled & 42 & 69 \\
\hline Thatched & 138 & \\
\hline
\end{tabular}




\begin{tabular}{|l|l|l|}
\hline Toilet facility available & & \\
\hline Water seal latrine & 30 & 15 \\
\hline Pit latrine & 52 & 26 \\
\hline No latrine & 118 & 59 \\
\hline Source of cooking fuel & & \\
\hline Fire wood & 161 & 80.5 \\
\hline Dung & 21 & 10.5 \\
\hline LPG gas & 3 & 1.5 \\
\hline Firewood and dung & 2 & 1 \\
\hline Firewood and LPG gas & 13 & 6.5 \\
\hline Main source of drinking water & & \\
\hline Well & 11 & 5.5 \\
\hline Tube well & 180 & 90 \\
\hline Municipal tap & 5 & 2.5 \\
\hline Municipal tap & 5 & 2.5 \\
\hline Tube well and municipal tap & 4 & 2 \\
\hline Age at marriage & & \\
\hline$<18$ & 65 & 32.5 \\
\hline $10-20$ & 121 & 60.5 \\
\hline 20 and more & 14 & 7 \\
\hline
\end{tabular}

On analysis of the trend of delivery, home deliveries were 151 (75.5\%) and hospital deliveries 49 (25.5\%). Evaluation was done based on variables of educational status, antenatal visits and daily family income of the respondents (Table 2). The highest number of hospital delivery (100\%) was seen in women with education SLC and above, followed by $57.7 \%$, women who had completed their four and more antenatal visits. There is a strong association of education with delivery practice $(\mathrm{p}=0.0014)$. The highest number (41.4\%) of hospital delivery were found in women with family income of NRs. 500 and above. Majority $(95 \%)$ of the umbilical cord was cut by new blade (Figure 1). Most (75.5\%) new born babies were fed with colostrums (Table 3). The colostrum was given more (98\%) babies born in hospital than home. 
Table 2: Place of delivery of the women by different variable

\begin{tabular}{|c|c|c|c|c|c|}
\hline \multirow[t]{2}{*}{ Educational status } & \multicolumn{2}{|c|}{ Place of delivery } & \multirow{2}{*}{$\begin{array}{c}\text { Total } \\
(n=200)\end{array}$} & \multirow[t]{2}{*}{$\mathrm{X}^{2}$ value } & \multirow[t]{2}{*}{$P$ value } \\
\hline & $\begin{array}{c}\text { Home } \\
(n=151) \\
(75.5 \%)\end{array}$ & $\begin{array}{c}\text { Hospital } \\
(n=49) \\
(25.5 \%)\end{array}$ & & & \\
\hline Illiterate & $104(82.5)$ & $22(17.5)$ & 126 & & \\
\hline Literate but not schooling & $24(75)$ & $8(2.5)$ & 32 & $13.15^{\star}$ & 0.0014 \\
\hline School education & $23(62.2)$ & $14(37.8)$ & 37 & & \\
\hline SLC and above & $0(0.0)$ & $5(100)$ & 5 & & \\
\hline \multicolumn{6}{|l|}{ Ante-natal care } \\
\hline No visit & $74(93.7)$ & $5(6.3)$ & 79 & 13.15 & 0.0014 \\
\hline $1-3$ visits & $66(69.5)$ & $29(30.5)$ & 95 & & \\
\hline 4 and more visits & $11(42.3)$ & $15(57.7)$ & 26 & & \\
\hline \multicolumn{6}{|l|}{ Family income (Daily) } \\
\hline *NRs. 50-199 & $63(80.8)$ & $15(19.2)$ & 78 & & \\
\hline NRs. 200-499 & $71(76.3)$ & $22(23.7)$ & 93 & 5.67 & 0.059 \\
\hline NRs. 500 and more & $17(58.6)$ & $12(41.4)$ & 29 & & \\
\hline
\end{tabular}

${ }^{\star}$ Considering school education and above Note : ${ }^{* 1}$ USD = NRs. 90/-

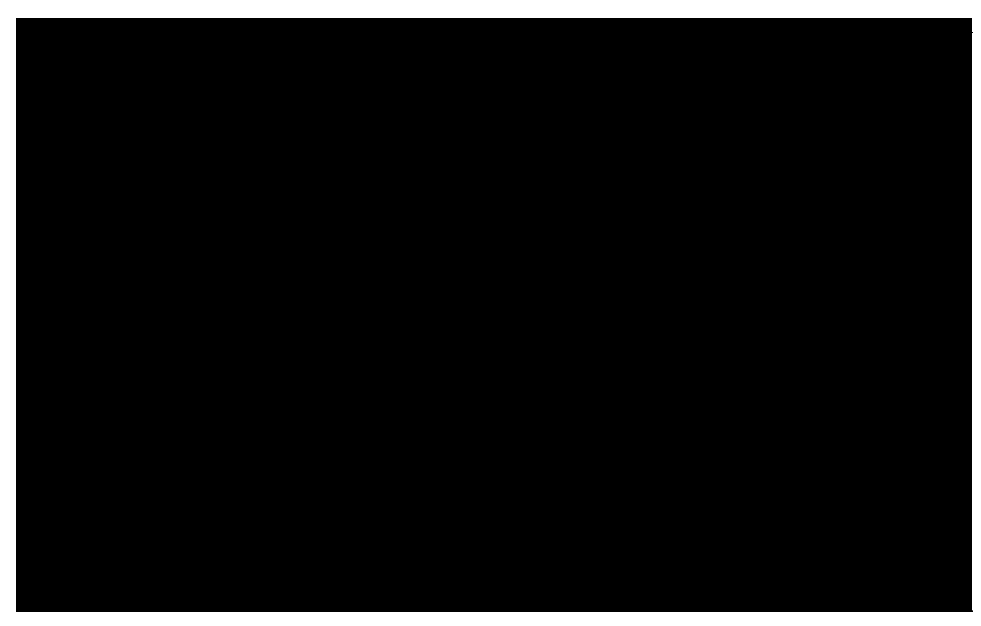

Fig. 1: Instrument use to cut umbilical cord of the new born

Table 3: Feeding of colostrums milk to baby 


\begin{tabular}{|l|l|l|l|l|l|}
\hline \multirow{2}{*}{$\begin{array}{c}\text { Place of } \\
\text { delivery }\end{array}$} & \multicolumn{1}{|c|}{ Feeding colostrums milk to baby } & Total & \multirow{2}{*}{$\mathbf{X}^{2}$ value } & \multirow{2}{*}{ P value } \\
\cline { 2 - 5 } & \multicolumn{1}{|c|}{ Yes } & \multicolumn{1}{|c|}{ No } & & \\
\hline Home & $104(68.9)$ & $47(31.1)$ & $151(75.5)$ & & \\
\hline Hospital & $47(98)$ & $2(2.00)$ & $49(24.5)$ & 22.48 & $<0.001^{*}$ \\
\hline Total & $151(75.5)$ & $49(24.5)$ & $200(100)$ & & \\
\hline
\end{tabular}

* Highly significant

\section{Discussion}

Of the 200 Muslim women interviewed, most $(83 \%)$ were house wives. Along with our strivings to locate eligible women by house to house survey conducted with the cooperation of Female Community Health Volunteer (FCHVs) and community leaders, there must be only a few, if any, women not included in our study population. The proportion of institutional delivery, in the interviewed population, was $24.5 \%$. Very limited research has been conducted in maternal health in Nepal, no any clearly record data are available either on the trend of home or hospital delivery in general population or based on certain ethnic groups. According to demographic and health survey, health professionals assisted the $18 \%$ institutional delivery among women in less than 20 years of age in 2006. ${ }^{11}$ In the study group, we recorded $24.5 \%$ institutional delivery; it is about $7 \%$ more than earlier recorded, which is good signs, but considering the interval of 7 years (2006-2013), it cannot be considered very ideal in certain ethnic group even in national average. This study has revealed that lack of awareness, level of women education, cost involved in available health facilities, and prohibition by the head of the family are the reasons of not delivering babies in health institutions. All (100\%) women with SLC and above education had delivered their babies in health institutions illiterate women. Whereas only $17.5 \%$ of delivered babies in health institute. Women with more education were a positive aspect for utilization of the health facilities for delivering babies in this study. This finding also support studies conducted in different part of Asia and Africa. ${ }^{12}$ Another study conducted within 15 different ethnic groups in Makwanpur district, of Nepal shows that $90 \%$ births took place at home. ${ }^{13}$ The similar study shows that, the proportion of home delivery were higher in rural: $(20 \%$ in Kathmandu Metropolitan, 39\% VDCs of Kathmandu district and 90\% VDCs in Dhading district). ${ }^{14}$ These variations of percentage distribution about institutional delivery due to various authors are likely to be due to difference in study samples sizes, ethnic groups, adopted research methodology and definition of health 
seeking behavior in their studies. Nepalese husbands generally do not want their pregnant wives to be examined by male doctors. ${ }^{15}$ That may also be socio cultural factor presenting delivering babies in health institution. In a Nigerian study, $41 \%$ of the mothers who did not deliver child in hospital explained that they could not afford the hospital bill and $31 \%$ said that they had inadequate transportation facilities. $^{16}$ In Kenya the most significant predictors of choosing home delivery were the distance from the household to near maternity hospital. ${ }^{17}$ Unaffordable hospital cost of delivery and distance of the hospital are main causes of babies not being delivered in hospital are the findings of Nigerian and Kenyan study. ${ }^{16}$ These findings may be applicable in Nepal also due to difficult geographical terrain. It is difficult for the pregnant mother to be brought to the health institutions in mountains, hills and difficult rugged terrain. However other studies in various countries have clearly demonstrated that women's education has strong and consistent effect on reproductive health outcomes, women who had SLC and above education have similar finding in present study.

Looking into all these facts about home deliveries, Government's of Nepal wants to encourage hospital (health institution: Sub$\mathrm{HP}, \mathrm{HP}, \mathrm{PHCC})$ delivery through Safe
Delivery Incentive Program (SDIP). This was lunched in 2005 in response to mounting evidence of the high cost faced by household trying to access care of child birth ${ }^{18}$ and low $(19 \%)$ coverage of skill birth attendants. ${ }^{19}$ Ante-natal care is another associated factor of home or hospital delivery of women. Mothers who did not seek ante-natal care during pregnancy were 4.5 times more likely choose delivery at the home. ${ }^{20}$ Our study has found women who did not take a single antenatal visit of whom $93.7 \%$ had home delivery and $6.3 \%$ hospital delivery. Higher educational attainment of women had a positive influence on the utilization of antenatal care (ANC) services in the studied population as also observed in other studies. ${ }^{21,22}$ This finding is also similar to our findings that the illiterate women (63\%) had, home (82.5\%) and hospital (17.5\%) deliveries. National level the institutional (Hospital, PHCC, Health Post, sub-health post) the delivery is 43.3 percent under the Aama program and 43 percent received the transport incentives in year $2012^{23}$.

\section{Conclusion}

Only one fourth of the women of the study population had delivery in health institution. Health institutional delivery was seen more in women who were more educated and had multiple antenatal visit. This warrants 
reproductive education strengthening in this group of women.

\section{References}

1. World Health Organization (WHO): Mortality Country Fact Sheet. World Health Statistics 2006 [http://www.who.int/whosis/mort/profiles/ mort searo npl nepal.pdf]

2. Faundes A, Rosenfield A, Pinotti JA. Maternity care in developing countries: relevance of new technological advances. Int. J Gynecol Obstet 1988, 24:103-109

3. Adam T, Lim S, Mehta S, Bhutta ZA, Fogstad $H$, Mathai $M$ et, al. Cost effectiveness analysis of strategies for maternal and neonatal health in developing countries BMJ 2005; 331:1107.

4. Health Evidence Network? What is the effectiveness of antenatal care? Copenhagen: WHO Regional Office for Europe; 2005.

5. McCaw-Binns A, La Grenada J, Ashley D. Under-users of antenatal care: a comparison of non-attendants and late attendants for antenatal care with early attendants. Soc Sio Med 2007; 40:1003-12.

6. WHO database on skilled attendant at delivery. Geneva: WHO: 2007. http://www.who.int/reproductive- health/global_monitoring/data.htm (Accessed on 7th January 2011)

7. WHO and UNICEF: Revised Estimated of Maternal Mortality, A new Approach by WHO, UNICEF and UNFPA (Geneva; WHO)

8. UNICEF: Maternity Mortality ratio too high in Nepal. http://news.xinhuanet.com/english/2009 -01/29/content_10734097.htm (Accessed on 2nd February 2011)

9. Resource Center for Primary Health Care: Health in Nepal realities and challenges Kathmandu. 1997

10. Kaunitz AM, Spence C Danielson TS, Rochat RW, Grimes DA: Perinatal and maternal mortality in a religious group avoiding obstetric care. Am J Obstet. Gynecolo. 1984, 150:826-831

11. Nepal Demographic and Health Survey. Population division Ministry of Health and Population Government of Nepal; 2006.

12. Yesudian PP. Impact of women's empowerment, autonomy and attitude on maternal health care utilization in India. Global Forum for Health Research, Forum 82005.

13. Mesko N. Osrin D, Tamang S, Shrestha B, Manandhar D, Manandhar M, Standing H Cosello A. Care for perinatal illness in rural Nepal: a descriptive 
study with cross-sectional and qualitative components. BMC International Health and Human Rights 2003; 3.

14. Bolam A, Manandhar DS, Shrestha P, Ellis M, Malla K, Chstello AM. Maternity care utilization in Kathmandu valley. Health Policy Plan 1998, 13:152-158.

15. Simkhada B, Van Teijlingen E, Porter M, Simkhada P. Major problems and key issues in maternal health in Nepal (Review article). Kathmandu Uni. Med J 2006; 4:258-263.

16. Fajemilehin BR. Factors influencing high rate of born before arrival babies in Nigeria a case control study in Ogbomsho. Int. J Nurs Stud. 1991, 28: 13-18.

17. Hodgkin D. Household characteristics affecting where mothers deliver in Rural Kenya. Health Econ 1996; 5:333-340.

18. Borghi J, Ensor T, Neupane BD, Tiwari S. Financial implications of skilled attendance at delivery in Nepal. Trop Med Int. Health 2006; 11 (2):228-23

19. Government of Nepal. Nepal Demographic and Health Survey. Kathmandu, Nepal: ORC Macro, MD, USA: 2007.

20. Jewkes R, Abrahams N, Mvo Z. Why do nurses abuse patients? Reflections from South African obstetric services. Soc Sci Med 1998, 47:1781-1795

21. Kulmala T, Vaahtera M, Ranniko J. The relationship between ante-natal risk characteristics, place of delivery and adverse delivery outcome in rural Malawi. Acta Obstet. Gynaecol. Scand. 2000; 79:984-90

22. Kabir M, lliyasu Z, Abubakar IS, Sani AA. Determinants of utilization of antenatal care services in Kumotso village, Northern Nigeria. Trop. Doc. 2005; 35:110-111

23. Government of Nepal DoHS Annual Report 2068/69, 2011/2012 page ii. 